\title{
Effect of endometriosis on ovulation, ovum pickup, fertilization and tubal transport in the rabbit
}

\author{
G. A. J. Dunselman, J. A. Land, P. X. J. M. Bouckaert and J. L. H. Evers \\ Department of Obstetrics and Gynaecology, Maastricht University Hospital, P.O. Box 1918, \\ 6201 BX Maastricht, The Netherlands
}

\begin{abstract}
Summary. In 25 rabbits (Group E) endometrium from the right uterine horn was transplanted on to the peritoneum. In 25 rabbits (Group C) fat was transplanted. After a recovery period of 12 weeks the does were mated, and killed $24 \mathrm{~h}$ later. In Group E the implants had changed into cysts of $5-15 \mathrm{~mm}$ in diameter. Histological examination revealed endometrial glands and stroma in every specimen. Periadenexal adhesions did not develop in any animal. No differences were found between Groups $\mathrm{C}$ and $\mathrm{E}$ in the number of corpora lutea, the recovery rate, the fertilization rate and the transport of fertilized ova. These findings indicate that endometrial implants in the rabbit have no influence on the ovulatory mechanism, the pickup function of the oviduct, the fertilization rate or on the transport of fertilized ova. Taking into account the restrictions of a rabbit model, it is suggested that the decreased fecundity in mild endometriosis in the human may be caused by disturbances in post-fertilization events, i.e. development of the pre-implantation embryo or implantation.
\end{abstract}

Keywords: endometriosis; ovulation; ovum pickup; fertilization; tubal transport

\section{Introduction}

Patients with mild endometriosis have a monthly fecundity rate which is considerably below that of the general population (Olive \& Haney, 1986). The reasons for this decreased fecundity, in particular when Fallopian tubes and ovaries are free of adhesions, remain unclear. Disturbances in folliculogenesis (Rönnberg et al., 1984; Wardle et al., 1985), ovulation (Soules et al., 1976; Brosens et al., 1978; Lesorgen et al., 1984), ovum pickup by the Fallopian tubes (Werlin et al., 1984; Suginami et al., 1986), fertilization (Wardle et al., 1985) and implantation (Chillik et al., 1985) all have been suggested as a cause. Changes in the peritoneal milieu secondary to endometrial implants might cause these disturbances. There is evidence for an increased number of more active, peritoneal macrophages in patients with endometriosis (review by Berger \& Rock, 1985). Prostaglandins and proteolytic enzymes produced by macrophages might cause ovulatory dysfunction and altered tubal function (ovum pickup and transport). Altered tubal transport of the fertilized ovum can lead to an untimely arrival in the uterine cavity with subsequent implantation problems. The enhanced activity of the macrophage population may affect fertilization and implantation by influencing the immune system and by phagocytosis.

Hahn et al. (1986) have reported that the decrease in fecundity, which they observed in rabbits with endometrial implants, was due to implantation failure. To study possible causes of subfertility in endometriosis, we investigated events in the periovulatory period, i.e. ovulation, ovum pickup, fertilization and tubal transport of fertilized ova in rabbits with mild endometriosis.

\section{Materials and Methods}

Virgin Dutch belted rabbits were used. The 50 does were caged individually at $20^{\circ} \mathrm{C}$ with a photoperiod of $12 \mathrm{~h}$ light: $12 \mathrm{~h}$ dark. They were fed $150 \mathrm{~g}$ of rabbit chow daily and allowed water ad libitum. Before surgery each doe received $125 \mathrm{mg}$ ampicillin prophylactically by intravenous injection. Anaesthesia was induced with $0.2 \mathrm{mg}$ atropine $/ \mathrm{kg}$ and 
$0.5 \mathrm{ml}$ Hypnorm $/ \mathrm{kg}$ (10 mg fluanizone and $0.2 \mathrm{mg}$ phentanyl per ml: Duphar, Amsterdam, The Netherlands) intramuscularly. As soon as anaesthesia was achieved, each doe was intubated with an endotracheal tube. A mixture of halothane $(0 \cdot 5-1 \cdot 0 \%)$, oxygen ( 1 litre $/ \mathrm{min}$ ) and nitrous oxide ( 2 litres $/ \mathrm{min}$ ) was given through a closed-loop inhalation anaesthesia system (infant ventilator, MK2; Keuskamp, Amsterdam, The Netherlands).

In all 50 rabbits a $1-\mathrm{cm}$ segment of the right uterine horn as well as adipose tissue from the juxta-uterine fat was resected. After resection, the uterine horn was reanastomosed and the defect in the fat tissue closed by microsurgical methods. In 25 rabbits (Group E) the resected uterine horn was opened longitudinally and divided into four equal parts. These pieces of uterine tissue (consisting of endometrium, muscularis and serosa) were sutured onto the peritoneum at the right lateral abdominal wall, adjacent to uterus and ovary, with the serosal side of the uterine tissue facing the peritoneum, and the endometrium facing the peritoneal cavity, using 6.0 Prolene (Ethicon, Sommerville, NJ, U.S.A.). In 25 rabbits (Group C) the fat was divided into four equal parts and sutured onto the peritoneum in a comparable way. In Group $E$ the fat tissue was discarded and in Group $C$ the uterine tissue was discarded. The abdominal wall was closed in two layers with everting interrupted sutures. After a recovery period of 12 weeks the does were mated with a buck of proven fertility. To ensure and synchronize ovulation the does were given 125 i.u. hCG (Pregnyl: Organon, Oss, The Netherlands). The does were killed $24 \mathrm{~h}$ after mating, i.e. $12 \mathrm{~h}$ after ovulation (Harper, 1961 ). Anaesthesia was induced with $0.5 \mathrm{mg}$ xylazine $/ \mathrm{kg}$ (Rompun: Bayer, Leverkusen, West Germany) and $0.4 \mathrm{ml}$ ketamine/kg (Ketaset: Bristol Laboratories, Syracuse, NY, U.S.A.) by intramuscular injection. An overdose of pentobarbitone sodium was administered intravenously and laparotomy was performed.

The abdominal cavity was carefully inspected for adhesions. The adhesions were scored, considering both extent and type of adhesion, as absent, mild (filmy adhesions) or moderate (dense adhesions). Adhesions from bladder fat, intestines and uterus to the endometrial implants were considered to have less consequence for fertility than adhesions from ovaries and oviducts to endometrial implants.

The implants were excised for histological examination. The patency of the right reanastomosed uterine horn was tested. The ovaries and oviducts were excised. The ovaries were examined under a stereomicroscope (Wild M8) to count the number of corpora lutea in each ovary. The oviducts were divided into three parts representing the ampullary segment, the ampullary-isthmic junction and the isthmic segment. The three segments of both oviducts were flushed with $5 \mathrm{ml}$ Hepes-buffered Whittingham's T6 culture medium adjusted to pH 7.4 (Quinn et al., 1984). The flushings were checked for the presence of ova and embryos under a stereomicroscope (Wild M8). The numbers of fertilized ova and the segment from which they were retrieved were noted. From these data the tubal transport index $24 \mathrm{~h}$ after mating was determined. The recovery rate, the fertilization rate and the tubal transport index were determined for each oviduct separately. Criteria for fertilization were the presence of spermatozoa in the perivitelline space, the presence of two polar bodies, the presence of two pronuclei, or cleavage.

The results obtained were compared between the right and left oviducts in each group, and between right oviducts and left oviducts for Groups C and E. Statistical analysis was performed using the Wilcoxon rank sum test for paired samples comparing right and left sides. The Wilcoxon rank sum test for unpaired samples was used to compare Groups E and C.

\section{Results}

The mean ( \pm s.d.) duration of the operation was $53 \pm 8 \mathrm{~min}$ in Group E, and $51 \pm 6 \mathrm{~min}$ in Group C. Body weights at autopsy were $2981 \pm 212 \mathrm{~g}$ in Group E and $2896 \pm 338 \mathrm{~g}$ in Group C $(P>0.05)$.

In all rabbits of Group E, the implants of the uterine tissue appeared to have developed into cysts filled with clear yellow or dark brown fluid. The diameter of the cysts ranged from 5 to $15 \mathrm{~mm}$. Histological examination revealed endometrial gland and stroma in every specimen. In Group C the fat tissue had not changed since the operation, and no endometrial tissue had developed.

In Group $E$ rabbits adhesions were absent in 4 animals, mild in 8 (only filmy adhesions) and moderate in 13 (dense adhesions). The equivalent figures for Group $\mathrm{C}$ does were 17 absent, 6 mild and 2 moderate $\left(P<0.001, \chi^{2}\right.$ test). However, the ovaries and oviducts were completely free of adhesions in every animal in both groups. The reanastomosed uterine horns were patent in every animal. As shown in Table 1, the number of corpora lutea, the recovery rates and the fertilization rates did not differ significantly when the results obtained from the right sides of the animals were compared to those from the untouched left sides, for rabbits in Groups $\mathrm{E}$ and $\mathrm{C}$. In the flushings of 4 oviducts no fertilized ova were found. There were also no differences in tubal transport index for the right and left sides of rabbits in Groups $\mathrm{C}$ and $\mathrm{E}$ or between groups.

Comparison of animals with no adhesions to animals with mild adhesions and to animals with moderate adhesions in Groups $\mathrm{E}$ and $\mathrm{C}$ showed no differences regarding number of corpora lutea, recovery rate, fertilization rate and tubal transport of fertilized ova. 
Table 1. Effect of endometrial implants on number of corpora lutea, recovery rate, fertilization rate and tubal transport of fertilized ova in rabbits

\begin{tabular}{|c|c|c|}
\hline & $\begin{array}{l}\text { Group E } \\
(\mathrm{N}=25)\end{array}$ & $\begin{array}{c}\text { Group C } \\
(\mathrm{N}=25)\end{array}$ \\
\hline \multicolumn{3}{|l|}{ No. of corpora lutea } \\
\hline Right ovary & $4.56 \pm 1.6$ & $3.88 \pm 1.5$ \\
\hline Left ovary & $3.96 \pm 1.5$ & $4 \cdot 44 \pm 1 \cdot 4$ \\
\hline \multicolumn{3}{|l|}{ Recovery rate $(\%)^{*}$} \\
\hline Right oviduct & $103 \cdot 20 \pm 27 \cdot 2$ & $104 \cdot 12 \pm 28 \cdot 8$ \\
\hline Left oviduct & $114 \cdot 60 \pm 86 \cdot 7$ & $106 \cdot 72 \pm 24 \cdot 4$ \\
\hline Right + left oviduct & $100 \cdot 88 \pm 9 \cdot 7$ & $102.64 \pm 10.7$ \\
\hline \multicolumn{3}{|l|}{ Fertilization rate $(\%) \dagger$} \\
\hline Right oviduct & $90 \cdot 24 \pm 24 \cdot 4$ & $91.68 \pm 22.8$ \\
\hline Left oviduct & $89 \cdot 36 \pm 24 \cdot 9$ & $93 \cdot 20 \pm 22 \cdot 1$ \\
\hline \multicolumn{3}{|c|}{ Tubal transport index $(\%) \ddagger$} \\
\hline Right oviduct & $97.90 \pm 10 \cdot 2$ & $98.33 \pm 5.7$ \\
\hline Left oviduct & $100 \pm 0$ & $96.33 \pm 9.4$ \\
\hline
\end{tabular}

Values are mean \pm s.d.

*(No. of ova and embryos recovered from oviduct/no. of CL) $\times 100$.

$\dagger$ (No. of fertilized eggs/no. of eggs recovered from oviduct) $\times 100$.

$\ddagger$ (No. of fertilized eggs recovered from ampullary-isthmic junction/total no. of fertilized eggs recovered from all 3 segments of oviduct) $\times 100$.

\section{Discussion}

In rabbits, Schenken \& Asch (1980) found a 50\% decrease in fertility rate in rabbits with surgically induced endometriosis. The decrease in fertility was concluded to be due to failure of ovulation which was, according to the authors, not related to adhesions. However, 4 out of 5 rabbits with adhesions in their study did not ovulate. A significantly reduced ovulation rate in rabbits with endometriosis confirmed these findings (Schenken \& Walters, 1986). The fertilization rates were not significantly different between groups of rabbits with and without endometrial implants, but the recovery rate in the endometriosis group was severely reduced (Schenken \& Walters, 1986). This reduced recovery rate was considered to be caused by ovarian or fimbrial adhesions. Werlin et al (1984) found reduced ovum recovery rates in monkeys with induced endometriosis when adhesions involved the fimbria and ampulla. Schenken et al. (1984) reported a reduced incidence of ovulatory cycles in monkeys with moderate and severe endometriosis, in contrast to animals with microscopic and mild endometriosis, in which the incidence of ovulatory cycles was not different from control animals. These results are in agreement with the findings of our study: there was no difference in number of corpora lutea in rabbits with endometrial implants, but without adnexal adhesions, compared to control animals. Because of the absence of adnexal adhesions the endometrial implants in our study might mimic more closely the stages of minimal and mild endometriosis in the human.

The recovery rates of embryos in our study did not differ between the groups studied and suggest an adequate pickup function of the oviducts in all animals. The tubo-ovarian relationship, considered to be critical to ovum pickup, was not disturbed, presumably because of the absence of periadnexal adhesions. Therefore, the differences observed by previous investigators (Schenken \& Asch, 1980; Schenken et al., 1984; Werlin et al., 1984; Schenken \& Walters, 1986) might have been due to imperfect surgical technique. We have demonstrated, by applying meticulous microsurgical techniques, that endometrial implants per se do not influence egg recovery rate in rabbits. However, 
the recovery rate exceeded $100 \%$ for one or both sides. If the cumulative recovery rate for both sides is $100 \%$, transmigration of ova from one ovary to the contralateral oviduct had presumably occurred, but if the recovery rate at both sides is over $100 \%$, polyovulation or undercounting of corpora lutea may have been the cause. Undercounting was reduced to a minimum in our study by inspecting the ovaries for newly ruptured follicles under a stereomicroscope. Polyovular follicular development has been described for rabbits (Adams, 1960; Al-Mufti et al., 1988). From in-vitro fertilization studies conflicting data have been reported on the fertilization of ova recovered in endometriosis patients. Normal fertilization rates have been found in patients with mild endometriosis (Chillik et al., 1985; O'Shea et al., 1985; Matson \& Yovich, 1986), but Wardle et al. (1985) have shown that even mild endometriosis affects the quality of oocytes and reduces the fertilization rate. In our model of mild endometriosis the fertilization rates of rabbits in the experimental group were not different from those in the control group. This is in agreement with the findings of Hahn et al. (1986). From their and our study it can be concluded that the reduced fecundity, at least in rabbits with endometrial implants, is due to post-fertilization problems.

Tubal transport of the preimplantation embryo may be hampered in patients with mild endometriosis. Transport of ova through the Fallopian tube is effected by both muscular contractions and ciliary activity. Ovarian steroids, adrenergic innervation and prostaglandins (PG) interact to influence oviducal contractility. In the rabbit, PGF-2 $\alpha$ accelerates tubal transport of fertilized ova and subsequently reduces the implantation rate (Chang \& Hunt, 1972; Salomy \& Goldstein, 1978). In women PGF-2 $\alpha$ in pharmacological doses has a stimulatory effect on the contractility of the muscle layer of the Fallopian tube (Coutinho \& Maia, 1971), but subsequent alteration of ovum transport could not be demonstrated (Croxatto et al., 1978). The role of endogenous PG in the spontaneous motility of the human Fallopian tubes is controversial (Elder et al., 1977). Moreover, peritoneal fluid PG concentrations in endometriosis are reported to be unchanged by some (Sgarlata et al., 1983; Rock et al., 1986), and increased by others (Drake et al., 1981; Ylikorkala et al., 1984). Therefore a causal relationship between peritoneal fluid PG and altered tubal transport, resulting in impaired fertility in endometriosis, is as yet unproven. The conflicting results obtained in measuring peritoneal fluid PG can be partly explained by methodological problems (Rock et al., 1986). However, the existence of two types of endometriosis, i.e. intra- and retro-peritoneal, as described by Vasquez et al. (1984), might also be responsible for the differences found. Schenken \& Asch (1980) found increased levels of peritoneal fluid PGF in rabbits with surgically induced endometriosis. They suggested that the increased levels of PGF could alter ovum transport. In a subsequent study, however, Schenken \& Walters (1986) did not find a difference in tubal transport of fertilized ova in rabbits with endometriosis compared to controls. The results of our study are in agreement with the data reported by Schenken \& Walters (1986): at $24 \mathrm{~h}$ after mating, i.e. $12 \mathrm{~h}$ after ovulation, over $95 \%$ of fertilized ova were retrieved from the ampullary-isthmic junction on both sides in all animals studied (Table 1). Comparison of these data with figures reported in the literature (Land et al., 1987) reveal no marked differences with normal tubal transport in the rabbit. The results obtained indicate that in the rabbit endometrial implants without periadnexal adhesions have no influence on tubal transport of fertilized ova during the first $24 \mathrm{~h}$ after mating.

Our results, obtained with rabbits with mild endometriosis, have to be interpreted with some caution in trying to explain endometriosis-associated subfertility in the human. The endometrial implants in the rabbit, although histologically consistent with endometriosis, are not necessarily identical with endometriosis. Taking these restrictions into account, it is suggested that, since no differences were found in ovulation, ovum pickup, fertilization and tubal transport in the rabbit with endometrial implants, the decreased fecundity found with mild endometriosis in the human may be attributed to other, not implant-related, properties of this enigmatic disease, or may be caused by post-fertilization problems, e.g. disturbances in early embryonic development or implantation. 


\section{References}

Adams, C.E. (1960) Studies on prenatal mortality in the rabbit, Oryctolagus cuniculus; the amount and distribution of loss before and after implantation. $J$. Endocr. 19, 325-344.

Al-Mufti, W., Bomsel-Helmreich, O. \& Christidès, J.Ph. (1988) Oocyte size and intrafollicular position in polyovular follicles in rabbits. J. Reprod. Fert. 82, 15-25.

Berger, N.G. \& Rock, J.A. (1985) Peritoneal fluid environment in endometriosis. Sem. Reprod. Endocrinol. 3, 313-318.

Brosens, I.A., Koninckx, P.R. \& Corveleyn, P.A. (1978) A study of plasma progesterone, oestradiol-17ß, prolactin and LH levels, and of the luteal phase appearance of the ovaries in patients with endometriosis and infertility. Br. J. Obstet. Gynaec. 85, 246-250.

Chang, M.C. \& Hunt, D.M. (1972) Effect of prostaglandin F $2 \alpha$ on the early pregnancy of rabbits. Nature, Lond. 236, 120-121.

Chillik, C.F., Acosta, A.A., Garcia, J.E., Perera, S., Van Uem, J.F.H.M., Rosenwaks, Z. \& Jones, H.W. Jr (1985) The role of in vitro fertilization in infertile patients with endometriosis. Fert. Steril. 44, 56-61.

Coutinho, E.M. \& Maia, H.S. (1971) The contractile response of the human uterus, fallopian tubes, and ovary to prostaglandins in vivo. Fert. Steril. 22, 539-543.

Croxatto, H.B., Ortiz, M.E., Diaz, S., Hess, R., Balmaceda, J. \& Croxatto, H.-D. (1978) Studies on the duration of egg transport by the human oviduct. Am. J. Obstet. Gynec. 132, 629-634.

Drake, T.S., O'Brien, W.F., Ramwell, P.W. \& Metz, S.A. (1981) Peritoneal fluid thromboxane $B_{2}$ and 6-ketoprostaglandin $\mathrm{F}_{1 \alpha}$ in endometriosis. Am. J. Obstet. Gynec. 140, 401-404.

Elder, M.G., Myatt, L. \& Chaudhuri, G. (1977) The role of prostaglandins in the spontaneous motility of the fallopian tube. Fert. Steril. 28, 86-90.

Hahn, D.W., Carraher, R.P., Foldesy, R.G. \& McGuire, J.L. (1986) Experimental evidence for failure to implant as a mechanism of infertility associated with endometriosis. Am. J. Obstet. Gynec. 155, 1109-1113.

Harper, M.J.K. (1961) The time of ovulation in the rabbit following the injection of luteinizing hormone. $J$. Endocr. 22, 147-152.

Land, J.A., Evers, J.L.H., Boeckx, W.D. \& Brosens, I.A. (1987) Ovum transport after microsurgical anastomosis of the rabbit oviduct. J. Reprod. Med. 32, 103-106.

Lesorgen, P.R., Wu, C.H., Green, P.J., Gocial, B. \& Lerner, L.J. (1984) Peritoneal fluid and serum steroids in infertility patients. Fert. Steril. 42, 237-242.

Matson, P.L. \& Yovich, J.L. (1986) The treatment of infertility associated with endometriosis by in vitro fertilization. Fert. Steril. 46, 432-434.

Olive, D.L. \& Haney, A.F. (1986) Endometriosisassociated infertility: a critical review of therapeutic approaches. Obstet. Gynecol. Surv. 41, 538-555.
O'Shea, R.T., Chen, C., Weiss, T. \& Jones, W.R. (1985) Endometriosis and in-vitro fertilisation. Lancet 2 , 723.

Quinn, P., Warnes, G.M., Kerin, J.F. \& Kirby, C. (1984) Culture factors in relation to the success of human in vitro fertilization and embryo transfer. Fert. Steril. 41, 202-209.

Rock, J.A., Rezai, N., Berger, N.A. \& Dubin, N.H. (1986) Cul-de-sac fluid in women with endometriosis: fluid volume and prostanoid concentration during the proliferative, ovulatory, and periovulatory phase of the menstrual cycle. In Endometriose 86, p. 19, Abstr.

Rönnberg, L., Kauppila, A. \& Rajaniemi, H. (1984) Luteinizing hormone receptor disorder in endometriosis. Fert. Steril. 42, 64-68.

Salomy, M. \& Goldstein, P.J. (1978) Prevention of pregnancy in rabbits using vaginal application of prostaglandin F2a. Fert. Steril. 29, 456-458.

Schenken, R.S. \& Asch, R.H. (1980) Surgical induction of endometriosis in the rabbit: effects on fertility and concentrations of peritoneal fluid prostaglandins. Fert. Steril. 34, 581-587.

Schenken, R.S. \& Walters, M.D. (1986) Ovulation and tubal transport in rabbits with endometriosis. Proc. Soc. Gynecol. Invest. p. 215, Abstr.

Schenken, R.S., Asch, R.H., Williams, R.F. \& Hodgen, G.D. (1984) Etiology of infertility in monkeys with endometriosis: luteinized unruptured follicles, luteal phase defects, pelvic adhesions, and spontaneous abortions. Fert. Steril. 41, 122-130.

Sgarlata, C.S., Hertelendy, F. \& Mikhail, G. (1983) The prostanoid content in peritoneal fluid and plasma of women with endometriosis. Am. J. Obstet. Gynec. $147,563-585$.

Soules, M.R., Malinak, L.R., Bury, R. \& Poindexter, A. (1976) Endometriosis and anovulation: a coexisting problem in the infertile female. Am. J. Obstet. Gynec. $125,412-417$.

Suginami, H., Yano, K., Watanabe, K. \& Matsuura, S. (1986) A factor inhibiting ovum capture by the oviductal fimbriae present in endometriosis peritoneal fluid. Fert. Steril. 46, 1140-1146.

Vasquez, G., Cornillie, F. \& Brosens, I.A. (1984) Peritoneal endometriosis: scanning electron microscopy and histology of minimal pelvic endometriotic lesions. Fert. Steril. 42, 696-703.

Wardle, P.G., McLaughlin, E.A., McDermott, A., Mitchell, J.D., Ray, B.D. \& Hull, M.G.R. (1985) Endometriosis and ovulatory disorder: reduced fertilisation in vitro compared with tubal and unexplained infertility. Lancet 2, 236-239.

Werlin, L.B., diZerega, G.S. \& Hodgen, G.D. (1984) Endometriosis: effect on ovulation, ovum pickup, and transport in monkeys: an interim report. Fert. Steril. 35, 263S, Abstr.

Ylikorkala, O., Koskimies, A., Laatkainen, T., Tenhunen, A. \& Viinikka, L. (1984) Peritoneal fluid prostaglandins in endometriosis, tubal disorders, and unexplained infertility. Obstet. Gynecol. 63, 616-620.

Received 22 April 1987 